\title{
Tardio, porém viçoso: Poe contista no Brasil
}

\section{A long time coming, but then Bountiful: \\ Poe as a short story writer in Brazil}

Denise Bottmann*

Abstract: This essay describes Poe's historical fortune as a short-story writer in Brazil since the first anthology printed in 1903 through April 2012.

Keywords: Edgar Allan Poe; translation; historiography.

Resumo: Este artigo apresenta um histórico das traduções dos contos de Edgar Allan Poe publicadas em livro no Brasil, desde sua primeira edição em 1903 até abril de 2012.

Palavras-chave: Edgar Allan Poe; tradução; historiografia.

\footnotetext{
*Historiadora, pesquisadora e tradutora. E-mail: dbottmann@gmail.com. 


\section{O painel}

Fato é que...

Edgar Allan Poe, o ficcionista, estreia na tradução brasileira em livro em data relativamente tardia: 1927.

Não é que não conhecêssemos Poe antes disso. Sua obra em poesia e prosa, mesmo se filtrada pelo prisma do simbolismo francês, era lida, analisada, imitada, cultuada desde os meados do século XIX. Poemas e contos eram esparsamente traduzidos e publicados em algum periódico da imprensa local desde os anos 1870, e a célebre tradução de Machado de Assis de The Raven veio à luz em 1883.

Por isso é tanto mais singular que, desde a publicação de seus primeiros contos nos Estados Unidos, tenham-se passado quase cem anos para dispormos de nosso primeiro Poe contista em livro. E, ainda por cima, num volume destinado ao público infanto-juvenil.

\section{Prenúncios}

Para entender como isso se deu, temos de voltar ao começo do século XX. Pois, na verdade, o primeiro livro de ficção de Edgar Allan Poe no Brasil é publicado em 1903. O volume se chama Novellas Extraordinarias, e contém dezoito contos e mais "A gênese de um poema", a versão em prosa que Baudelaire fez do poema The Raven. É um belo voluminho, com o rebordo das páginas em dourado, a encadernação em tecido vermelho gravado com uma estampa floral (aliás, muito pouco poeana) também em dourado, em formato 18 x 11, com 344 páginas. Não traz introdução, prefácio, nota editorial ou biográfica. Apenas a página de rosto com os dados da publicação, et voilà, mergulhamos diretamente em "O Rei Peste" (The King Pest). 
A página de rosto merece atenção. Ela especifica: Edgar Pöe; Novellas Extraordinarias (Traducção Brasileira) H. Garnier, Livreiro-Editor.

Que a tradução é indireta, feita a partir do francês, fica evidente não só pela presença da baudelairiana "A gênese de um poema", mas também pela leitura acompanhando o original e a versão francesa. 0 surpreendente é que, a despeito da indicação "Traducção Brasileira" na página de rosto do livro, trata-se de simples cópia das traduções portuguesas de Poe feitas por Mécia Mouzinho de Albuquerque (1889 e 1890) e Christina Amélia Assis de Carvalho (1890 e 1891), publicadas na coleção "Bibliotheca Universal Antiga e Moderna", vols. 37, 61, 69 e 80 respectivamente, pela lisboeta Companhia Nacional Editora. Essa edição brasileira da H. Garnier teve mais algumas reedições, até 1919, na já então Livraria Garnier.

Apenas em 1921 sai outra antologia de Poe, com nota biográfica e oito contos em tradução de J anuário Leite, com o título de Contos de Imaginação e Mysterio, pela Annuario do Brasil, na coleção "Obras-Primas: Anthologia Universal", 4a, em volume cartonado, desta vez especificando que a tradução fora feita diretamente do inglês. Será reeditada em 1926, pela mesma editora. 0 que há de peculiar nesta tradução publicada pela Annuario do Brasil é que J anuário Leite também era português.

Assim, até 1926, embora dispondo de edições brasileiras com uma amostragem razoavelmente significativa da obra ficcional de Poe, não se pode dizer a rigor que houvesse traduções brasileiras de seus contos em livro.

\section{A chegada}

No ano de 1927, o crítico literário e tradutor Affonso de Escragnolles Taunay, recém-incumbido da série "Histórias Maravilhosas" na Bibliotheca da Adolescencia da editora Companhia Melhoramentos, seleciona, traduz e publica aquela que realmente pode ser considerada a primeira antologia brasileira de Edgar Allan Poe: Historias Exquisitas, com nove contos, prefácio, nota biográfica e pranchas ilustradas. 
No ano seguinte, como terceiro volume da mesma série, Taunay seleciona e traduz uma segunda antologia, que curiosamente - e decerto não por acaso - traz o mesmo título da edição da H. Garnier: Novellas Extraordinarias, com nota biográfica, seis contos e a nota sobre Hans Pfaall. Vale notar que, embora nenhuma das edições o especifique, estas também são traduções indiretas, pelo francês.

Na fase inicial do ingresso da prosa de Poe em livro no Brasil, há dois registros interessantes, em suporte mais efêmero. Em 1920, sai uma tradução anônima de 0 gato preto no semanário de cultura Leitura Para Todos, cujo principal destaque cabe às seis preciosas ilustrações que a acompanham, feitas por Oswaldo Goeldi, ainda jovem. Em 1922, temos uma tradução dramatizada de The Masque, "A mascarada interrompida", por Dioclécio D. Duarte, numa pequena brochura publicada pela editora O Norte.

\section{Primeiro balanço}

Voltando à produção estritamente editorial, ao cabo desses 25 anos que decorrem entre a primeira e a última dessas antologias - pela H. Garnier, Annuario e Melhoramentos -, ou seja, entre 1903 e 1928, o leitor brasileiro tem à disposição 31 contos de Poe, ou seja, quase a metade do cânone. Desses 31 contos, alguns se repetem entre as antologias, totalizando 42 traduções, das quais apenas dezesseis são efetivamente brasileiras, porém indiretas. Essa situação perdurará até 1943. Assim, durante quarenta anos de 1903 a 1943 - os contos de Poe que temos publicados em livro no Brasil são:

Mécia Mouzinho de Albuquerque, H. Garnier, 1903 (Cia. Nacional, 188990), tradução portuguesa apresentada como se fosse brasileira: O Rei Peste; Pequena Discussão com uma múmia; 0 gato preto; 0 homem das multidões; Colóquio entre Monos e Uma; Colóquio entre Eiros e Charmion; Poder da palavra; O poço e o pêndulo; 0 demônio da perversidade; William Wilson; Berenice; O escaravelho de ouro; Silêncio; Hop-Frog; 0 
Bottman, D. - Tardio, porém viçoso: Poe contista no Brasil

sistema do doutor Breu e do professor Pena (além da já referida "Gênese de um poema").

Christina Amélia Assis de Carvalho, H. Garnier, 1903 (Cia. Nacional, 189091), tradução portuguesa apresentada como se fosse brasileira: Duplo assassínio na rua Morgue; A carta roubada.

J anuário Leite, Annuario do Brasil, 1921, tradução portuguesa publicada originalmente no Brasil: Os crimes da rua Morgue; Ligeia; A verdade sobre o caso do sr. Valdemar; Leonor; O coração delator; O gato preto; Berenice; A mascarada da morte vermelha.

Affonso de Escragnolles Taunay, Melhoramentos, 1927 e 1928, por interposição do francês: O duplo crime da rua Morgue; A carta furtada; Manuscrito achado numa garrafa; Descida ao Maelstrom; A balela do balão; Metzengerstein; Reminiscências do snr. Augusto Bedloe; O diabo no campanário; 0 rei peste; 0 escaravelho dourado; A incomparável aventura de um tal Hans Pfaal; O sistema do doutor Alcatrão e do professor Pena; Hop Frog; A barrica de amontillado; A máscara da Morte Rubra; Nota a propósito de Hans Pfaal.

\section{Uma persistência indesejável}

A contrafação que inaugurou a presença de Poe ficcionista em livro no Brasil prosseguiu até 1988. Em 1925, a Editora Rochera lança um volume reproduzindo seis contos daquela suposta "traducção brasileira", com o título Duplo assassínio na rua Morgue. Com essa edição, inaugura-se também a abordagem sensacionalista de um Poe jocosamente anunciado como "leitura pouco recomendável às pessoas de espírito fraco" (ENGLEKIRK 1949: 105).

Tendo a Garnier encerrado suas atividades em 1934, suas Novellas Extraordinarias ressurgem em 1941 em dois volumes, pela editora O Livro de Bolso: Contos Fantásticos, sem crédito de tradução, e Novelas Extraordinárias, com a especificação "Tradução portuguesa, revista por Faria e Sousa". J untos, correspondem aos mesmos 18 contos já citados, além da 
mesma "Gênese de um poema" de Baudelaire, publicados naquela lisboeta "traducção brasileira" de 1903.

Em 1943, a Editora Cruzeiro do Sul lança Novelas Extraordinárias, com nove contos, idêntica à d'O Livro de Bolso, porém agora atribuindo a tradução diretamente a Faria Souza.

E continua-se a reeditá-las: em 1945, pelo Clube do Livro, como Novelas Extraordinárias; em 1972, pela Ordibra/ INL sob licença do CdL, como Histórias Extraordinárias, com tradução falsamente atribuída a J oão Teixeira de Paula; em 1981, numa coletânea chamada Horas de Terror, também pelo CdL; em 1988, mais uma vez pelo CdL, e também como Histórias Extraordinárias, com a mesma tradução, agora atribuída a José Maria Machado. Diga-se de passagem, o Clube do Livro, que adotava uma linha inspirada no Book-of-the-Month Club americano, mantinha tiragens de até 50 mil exemplares, bastante altas para os padrões brasileiros (MILTON 2002: 11).

\section{Calmaria, e alguns ventos}

Retornemos às traduções e edições legítimas. Entre 1928 e 1943 não se publicou em livro nenhuma tradução ou retradução de contos de Poe. Mas, em termos de magazines, vale a pena notar uma ligeira efervescência: em 1937 e 1938, na Revista Literária A Novela, da Livraria do Globo, saem as primeiras traduções brasileiras dos contos "O coração revelador" e "A queda da casa de Usher", este em tradução de Wilson Velloso; em 1941 e 1942, a Contos Magazine publica outros três contos de Poe, em tradução de R. K. Machado.

Apenas em 1943, voltamos a ter em livro novas traduções ou, melhor dizendo, uma tradução e duas retraduções: 0 mistério de Marie Roget, A máscara da morte rubra e A carta roubada, pela Vecchi, em tradução de Frederico Reys Coutinho e Líbero Rangel de Andrade.

Em 1944, sai pela Pongetti As aventuras de Arthur Gordon Pym, por Eloy Pontes. É também desta fase que podemos datar o início do uso 
Bottman, D. - Tardio, porém viçoso: Poe contista no Brasil

sistemático da tradução direta do inglês, salvo algumas exceções bem posteriores que veremos mais adiante.

\section{Agora sim}

O ano de 1944 é o annus mirabilis da fortuna de Poe no Brasil. A editora Globo (pertencente à Livraria do Globo citada acima) publica uma edição monumental, em três volumes, com mais de 1.400 páginas, com 0 título não muito exato de Poesia e Prosa/ Obras Completas. Essa edição trazia nada menos que toda a ficção completa, ${ }^{1}$ grande parte dos poemas (34 deles) e alguns ensaios de Poe, além de introdução e os estudos de Hervey Allen e de Baudelaire sobre 0 autor.

O trabalho hercúleo de tradução ficou a cargo de Milton Amado (poesia e prosa) e Oscar Mendes (a quatro mãos com Milton Amado na prosa, e responsável pela introdução e aparato crítico). Até 2011, quando foram lançadas no Egito as obras completas de Poe em tradução para o árabe, essa edição era, depois da edição francesa, a mais vasta poeana traduzida no mundo, um trabalho de fôlego realmente admirável.

Se a infeliz edição da Garnier corrompeu desde o berço a trajetória de Poe contista no Brasil durante 85 anos, de certo modo a edição da Globo a resgatou em grandíssimo estilo. Feitas as devidas vênias à iniciativa pioneira de Affonso Taunay em 1927-28, pode-se dizer que Poe no Brasil se divide em a.G. e d.G., em que pesem eventuais falhas de edição e/ ou tradução.

\footnotetext{
${ }^{1} \mathrm{O}$ conto "Von Kempelen and His Discovery" está incluído entre os ensaios nessa edição de 1944. A partir de 1965, a edição da Globo passa a ser publicada pela J osé Aguilar, mais tarde Nova Aguilar, com o título de Ficção Completa, Poesia e Ensaios. Embora conste na página de créditos que se trata da mesma versão de 1944, o conto "Von Kempelen" foi eliminado da seção de ensaios, sem, no entanto, ser incluído entre a ficção. Este que foi o último conto publicado por Poe em vida, publicado entre nós apenas em 1944, foi agora resgatado em [N.T.] Revista Literária em Tradução, III, 4 (abr. 2012), em tradução da autora deste artigo. Disponível em http:// www. notadotradutor.com/ edicoes.html. Agradecemos ao pesquisador Rodrigo Cardoso pelas preciosas informações sobre as diferenças entre essas edições.
} 


\section{A partir daí...}

Estabelecido Poe em toda a sua glória ficcional no Brasil, entre 1944 e 1958 seus contos passam a ter presença constante em antologias de autores variados, em outras traduções: Os norte-americanos: antigos e modernos ("O poço e o pêndulo", Lívio Xavier, Leitura, 1945); Os mais belos contos terroríficos dos mais famosos autores, séries 1 e 2 ("O enterramento prematuro", Frederico Reys Coutinho, e "O demônio da perversidade", J. da Cunha Borges, Vecchi, 1945); Visitantes da noite ("O coração revelador", Almiro Rolmes, Brasiliana, 1951); Contos e novelas de língua estrangeira II ("Pequena conversa com uma múmia", Yolanda Lulhier e Nádia Santos, Logos/ Edigraf, 1957); Mar de Histórias III ("O homem da multidão" e "A carta furtada", Paulo Rónai e Aurélio B. de Hollanda, J osé Olympio, 1958), além de vários sem identificação dos tradutores, como Maravilhas do conto universal (Cultrix, 1957), Obras-primas do conto norte-americano (Martins, 1958), Obras-primas do conto policial (Martins, 1955) Maravilhas do conto fantástico (Cultrix, 1958), entre muitos outros.

Ainda neste período, vale notar duas pequenas preciosidades: em 1948, Lygia Fagundes Telles traduz "O coração delator", que sai em Letras e Artes, suplemento literário do jornal carioca A Manhã. E em 1949 Lúcio Cardoso traduz e monta uma adaptação teatral do mesmo conto, encenada no mesmo ano pelo Teatro de Câmera no Rio de J aneiro.

Além da inclusão em miscelâneas de autores, Poe recebe novas antologias próprias nesse período entre 1944 e 1958: Contos de imaginação e mistério, pela Pinguim, em 1947, em tradução de Aurélio Lacerda (oito contos); O escaravelho de ouro e Os assassínios da rua Morgue (Álvaro Pinto de Aguiar, Melhoramentos, 1952); 0 fantasma da rua Morgue, com doze contos, pela Vecchi, com tradução de Frederico Reis Coutinho, em 1954; 0 mistério do gato preto, com oito contos de tradução anônima, pela Tecnoprint em 1954. 
Bottman, D. - Tardio, porém viçoso: Poe contista no Brasil

\section{Dois destaques}

Em 1958, é lançada mais uma antologia que criará história, por várias razões. Trata-se de Histórias Extraordinárias, pela Cultrix, com seleção, prefácio e tradução de José Paulo Paes, com 18 contos. $^{2}$ Para começar, é quando se introduz o título, de inspiração claramente baudelairiana, Histórias Extraordinárias. Veremos adiante os efeitos deste título, aparentemente tão inofensivo, sobre a fortuna de Poe no Brasil. Em segundo lugar, a seleção foi muito feliz, ajudando a desviar um pouco o foco excessivo no lado mais lúgubre ou terrorífico da ficção de Poe, adotado na Vecchi e outras.

Ademais, sendo apenas um volume e bastante representativo da prosa de Poe, era muito mais acessível ao leitor do que a edição da Globo em três alentados volumes. A partir de 1987, essa coletânea veio a ser distribuída pelo maior canal de venda domiciliar, o Círculo do Livro (com o título de Os melhores contos de Edgar Allan Poe), e em 2008 passou para o catálogo da editora Companhia das Letras.

Voltemos à nossa sequência cronológica e passemos agora ao segundo destaque desse período. Logo depois do lançamento de Histórias Extraordinárias, sai em 1959 outra antologia de qualidade pelo menos comparável à da Cultrix: Antologia de contos de Edgar Allan Poe, com 11 contos, em tradução de Brenno Silveira, outro renomado tradutor brasileiro, pela editora Civilização Brasileira.

Em 1970, certamente por razões de concorrência no mercado, essa antologia de Brenno Silveira sofre uma reformulação, ficando com 13 contos e o mesmo título da concorrente Cultrix, Histórias Extraordinárias. A partir de 1973 até 2003, no sistema de distribuição em bancas (Abril e Nova Cultural) e venda domiciliar (Círculo do Livro), as Histórias Extraordinárias da Civilização Brasileira praticamente dominam o mercado do grande público, em sucessivas

\footnotetext{
${ }^{2}$ Cabe notar, porém, que essa coletânea traz o conto "O escaravelho de ouro" com tradução atribuída a José Paulo Paes, sendo, porém, cópia irretocada da tradução feita por Almiro Rolmes Barbosa e Edgard Cavalheiro, publicada em 1942 pela Livraria Martins, na antologia As obras-primas do conto universal, conforme foi possível constatar após um alerta do tradutor Guilherme Braga em correspondência pessoal.
} 
reedições ampliadas (chegando a 16 contos), em tiragens na faixa de 70 mil ou mais exemplares por edição. A partir de 2010, essa coletânea volta ao mercado com o título de Antologia de contos extraordinários, pela BestBolso, do Grupo Record.

\section{Mais um breve balanço}

Assim, entre 1903 e 1959, podemos demarcar o cenário das traduções brasileiras de Poe contista da seguinte maneira: um início espúrio no início do século e uma relativa aridez por cerca de vinte anos; na década de 1920, algumas tímidas tentativas de firmar sua presença no país; em 1944, uma verdadeira explosão com a colossal publicação da obra quase completa; em 1958 e 1959, duas antologias muito felizes, bem equilibradas, com traduções fluentes de boa qualidade, com forte presença no mercado até a data de hoje.

\section{Consolidação}

Na década e meia entre 1959 e 1974, temos algumas novas antologias, por exemplo Histórias célebres, com nove contos, em tradução de Octavio Mendes Cajado (Saraiva, 1959); pela mesma Saraiva, em 1961, Os crimes da rua Morgue e outras histórias, com 11 contos em tradução de Aldo della Nina; Contos de Horror, pela Bruguera, em 1970, com oito contos, em tradução de Luiza Lobo.

Além disso, Poe é incluído em várias miscelâneas de autores (Maravilhas do conto amoroso; Maravilhas do conto policial; Obras-primas do conto de terror; Contos fantásticos; Contos de mistério e imaginação; As melhores histórias insólitas etc.). Tendo a Globo licenciado sua monumental edição para a J osé Aguilar, a partir de 1965 esta passa a publicá-la em volume 
Bottman, D. - Tardio, porém viçoso: Poe contista no Brasil

único de 1.022 páginas em papel bíblia, com o título Ficção completa, poesia \& ensaios. Em 1975, a Aguilar desmembra a obra, lançando um volume mais modesto de Contos de Terror, de Mistério e de Morte, favorecendo a vertente mais "gótica" dos contos de Poe.

Em 1974, a Ediouro lança 7 de Allan Poe, a que se segue 11 de Allan Poe em 1975, que somados resultarão nos 18 contos publicados em 1985 com o título de Histórias Extraordinárias de Allan Poe. 0 que há de interessante nessas edições - além da adoção do título Histórias Extraordinárias com fins visivelmente concorrenciais - é que não só a Ediouro é o maior grupo editorial brasileiro, com edições de bolso com preço acessível para o grande público, mas que esses contos em português vêm assinados por Clarice Lispector. Na verdade, são adaptações voltadas para o público juvenil, com texto resumido e bastante simplificado, muitas vezes baseando-se em traduções previamente existentes.

A essas alturas, há um mar de contos de Poe espalhados pelo Brasil, em mais de sessenta antologias diferentes - exclusivas de Poe e mistas com outros autores - e edições com apenas uma história, com mais de cinquenta tradutores (incluídos os espúrios e anônimos). A partir dos anos 1970, pode-se dizer com toda a certeza que Poe conhece o Brasil de norte a sul, plenamente integrado à bagagem mínima do leitor médio desde a adolescência, se não antes.

\section{O caso das Histórias Extraordinárias}

Também a partir dos anos 1970 e prosseguindo até 2005, tem-se a multiplicação das antologias, por mais variadas que sejam, portando o mesmo título de Histórias Extraordinárias: nada menos do que 16 coletâneas diferentes, de diferentes organizadores, cujo conteúdo varia de quatro a 18 contos. A própria Globo, que nos anos 1980 começa a subdividir a ficção completa, os ensaios e poemas em antologias variadas, para maior difusão da 
obra no mercado, cede à nova moda e em 1987 publica um volume de Histórias Extraordinárias.

Nessa estranha onda de multiplicação do mesmo título para obras diferentes, ainda em 1978 aconteceu um fenômeno bizarro, que se mantém até hoje, em várias editoras e junto ao público leitor: por um erro de atribuição, no prefácio da edição publicada pela Abril Cultural, afirmava-se que aquela sua coletânea intitulada Histórias Extraordinárias (a mesma que saíra em 1959 com o título de Antologia, salvo pequenas reformulações feitas em 1970) correspondia ao original Tales of the Grotesque and Arabesque. Por incrível que pareça, tal atribuição tão inexplicável - bastaria conferir os contos de uma e outra - foi adotada por outras editoras (como a Ediouro), que passaram a alegar que suas Histórias Extraordinárias eram traduções do original TGA.

Se lembrarmos como Poe era cioso da concepção unitária de suas coletâneas, é uma grande ironia que, a despeito de termos no Brasil mais de 500 traduções de seus contos, mais de 130 volumes diferentes com contos variados e 16 Histórias Extraordinárias distintas entre si, Tales of the Grotesque and Arabesque, como unidade de direito próprio, seja inédito entre nós. Aliás, e em decorrência deste simples fato, igualmente inédito em livro é seu prefácio de 1839, tão conciso, mas tão importante. ${ }^{3}$ Esse surpreendente lapso de 1978, veiculado por uma das gigantes editoriais brasileiras, perdura até hoje, fundamente arraigado, inclusive em referências de estudos literários e acadêmicos. ${ }^{4}$

\footnotetext{
${ }^{3}$ Este prefácio, inédito no Brasil até 2011, agora se encontra publicado digitalmente em [N.T.] Revista Literária em Tradução, II, 3, set. 2011, em tradução da autora deste artigo. Disponível em: 〈http:/ / www. notadotradutor. com/ revista3. html $>$.

${ }^{4}$ Para uma exposição mais pormenorizada dessa ocorrência, ver BotTMAnN, D. Alguns Aspectos da Presença de Edgar Allan Poe no Brasil.
} 


\section{Nas escolas}

Nos anos 1980, mais precisamente a partir de 1988, tem-se um novo fenômeno: a publicação de Poe por editoras especializadas em livros didáticos e paradidáticos, fornecedoras de livros nas licitações do governo para abastecimento das bibliotecas e escolas públicas. É o caso da Scipione com a adaptação para o público infanto-juvenil de Os assassinatos da rua Morgue, feita por Ricardo Gouveia, e da Ática na coleção Para Gostar de Ler, "O coração delator" no volume Contos Universais, em tradução de Márcia Pedreira. Segue-se em 1995 a FTD, outra potência no setor de didáticos e paradidáticos, com 0 mistério de Marie Roget, em adaptação de Ari Nicodemos Trentin.

Esse segmento tem se desenvolvido com vigor, abastecido mais recentemente com 0 gato preto e outras histórias, também pela Scipione, em adaptação de Ricardo Gouveia. A Ática, por sua vez, na mesma coleção didática Para Gostar de Ler, continua a publicar outros contos de Poe, como "Tu és o homem" (1992), "O gato negro" (1998), "Os fatos no caso de monsieur Valdemar" (2005). Com menos sucesso, mas visando ao mesmo segmento de didáticos, contam-se a Sol, com "A carta roubada" (1998), e a Atual, com "O escaravelho de ouro" (2006). Mais recentemente, e com maior projeção, temos a SM, em Leituras de Escritor, com "A carta roubada" (2008).

\section{Elementos episódicos}

Nos anos 1990, extinta a principal editora responsável por traduções espúrias de Poe no Brasil, o Clube do Livro, infelizmente sucederam-se outras publicações ilícitas: assim é que, desde 1999 até 2010, a editora Martin Claret publica em sucessivas reedições um volume de bolso com sete contos e 0 indefectível título de Histórias Extraordinárias, com tradução atribuída a Pietro Nassetti, na verdade cópia atamancada das traduções de Brenno Silveira. 
Na mesma década, em 1995, ressurge o uso da tradução indireta, desta vez pelo italiano, em Contos do Terror, pela Newton Compton, feita por Annunziata Capasso de Filippis, sem mencionar a interposição. A tradução indireta pelo francês reaparece em 2005, com Cláudia Ortiz, em mais um volume de Histórias Extraordinárias, com sete contos, pela Escala/ Larousse, este especificando a interposição. A Melhoramentos, por sua vez, a partir de 2006 cria uma coleção chamada "Histórias Extraordinárias", publicando contos de Poe em pequenos volumes individuais, em traduções a partir do espanhol, por Antonio Carlos Vilela, com a língua de interposição devidamente especificada.

\section{Concluindo}

É importante frisar que as novas tendências não substituem nem suplantam as anteriores: somam-se e entrelaçam-se a elas. Assim é que, atualmente, temos ao dispor do público brasileiro desde uma grandiosa edição praticamente completa até histórias em quadrinhos e a mais sanguinolenta pulp fiction, passando por todo o leque de edições críticas e anotadas, antologias exclusivas, antologias mistas, obras únicas, seleções temáticas, resgates de contos menos conhecidos, livros didáticos, adaptações do mais variado naipe, em traduções de qualidade e idoneidade variáveis, em edições simples em papel jornal ou de luxo, com ilustrações de artistas importantes.

É um panorama denso, luxuriante, com irregularidades e desníveis, onde Edgar Allan Poe está definitivamente instalado no Brasil. 


\section{Apêndice}

Segue-se uma listagem com o número aproximado de traduções de cada conto publicadas em livro no Brasil entre 1903 e abril de 2012:

Black Cat, The $\quad 36$

Purloined Letter, The 32

Murders in the Rue Morgue, The 30

Gold-Bug, The $\quad 26$

Pit and the Pendulum, The $\quad 21$

Cask of Amontillado, The 20

Masque of Red Death, The 20

Tell-Tale Heart, The 20

$\begin{array}{ll}\text { Berenice } & 16\end{array}$

Fall of the House of Usher, The 16

Oval Portrait, The 15

William Wilson 14

Imp of the Perverse, The 13

MS Found in a Bottle 13

Mystery of Marie Rogêt, The 13

Hop-Frog 12

Man of the Crowd, The 12

System of Doctor Tarr and Professor Fether,

The 12

$\begin{array}{ll}\text { Metzengerstein } & 11\end{array}$

Shadow - A Parable 11

Facts in the Case of M. Valdemar, The 11 
$\begin{array}{ll}\text { Descent into the Maelström, A } & 10\end{array}$

Silence: A Fable 9

Premature Burial, The 9

Narrative of Arthur Gordon Pym of Nantucket, The 8

Some Words With a Mummy 8

$\begin{array}{ll}\text { Ligeia } & 8\end{array}$

Devil in the Belfry, The 6

Unparalleled Adventure of One Hans Pfaal, The 6

King Pest 6

Visionary, The (Assignation, The) 6

Oblong Box, The 5

Tale of the Ragged Mountains, A 5

Never Bet the Devil Your Head 5

Colloquy of Monos and Una, The 5

Conversation of Eiros and Charmion, The 4

Power of Words, The 4

"Thou Art the Man" 4

Morella 4

Le Duc de I'Omelette 3

Mesmeric Revelation 3

Eleonora 3

Sphinx, The 3

Angel of the Odd, The 2

Balloon Hoax, The 2

Literary Life of Thingum Bob, Esq. 2

Man that was Used Up, The 2 
Bottman, D. - Tardio, porém viçoso: Poe contista no Brasil

Spectacles, The 2

Three Sundays in a Week 2

Lionizing 2

Business Man, The 1

Diddling Considered as One of the Exact
Sciences

Domain of Arnheim, The 1

Epimanes (Four Beasts in One) 1

How to Write a Blackwood Article 1

Island of the Fay, The 1

Landor's Cottage 1

$\begin{array}{ll}\text { Bon-Bom } & 1\end{array}$

Loss of Breath 1

Maelzel's Chess-Player ${ }^{5} \quad 1$

Mellonta Tauta 1

Mystification 1

Predicament, A 1

Tale of J erusalem, A 1

Thousand-and-Second Tale of Scheherazade,

The 1

$\begin{array}{ll}\text { Von Kempelen and His Discovery } & 1\end{array}$

Why the Little Frenchman Uses his Hand in a Sling 1

X-ing a Paragrab 1

Total de traduções, distribuídas em 145 publicações: 529

5 "O jogador de xadrez de Maelzel", embora seja um ensaio, está incluído entre os contos por ter sido publicado - sem créditos de tradução - numa antologia de Histórias Extraordinárias (Abril Cultural, 1978).

TradTerm, São Paulo, v. 22, Dezembro/2013, p. 89-106

www. usp. br/tradterm

http:// www. revistas. usp. br/ tradterm/ index 
O conteúdo detalhado das diversas publicações brasileiras dos contos de Poe desde 1903, com os respectivos créditos de tradução, bem como um amplo arquivo iconográfico das capas de primeira edição, pode ser consultado em edgar allan poe, no endereço «ttp:// eapoenobrasil. blogspot.com. br>.

\section{Referências bibliográficas}

\section{Fontes primárias:}

Acervos da Fundação Biblioteca Nacional; Biblioteca Nacional de Portugal; Brasiliana USP; Estante Virtual; The Edgar Allan Poe Society of Baltimore; catálogos digitais de bibliotecas universitárias e bancos de teses; acervo pessoal; comunicação pessoal com editoras, tradutores e/ ou sucessores e outros pesquisadores.

\section{Fontes secundárias:}

BotTMAnN, Denise. Alguns aspectos da presença de Edgar Allan Poe no Brasil. In: Tradução em Revista, 8, 2010: 1-19. Disponível em: বhttp:// www. maxwell.lambda. ele. pucrio.br/trad_em_revista. php?str Secao=input0>

DAGHLIAN, Carlos. Obras de e sobre Poe em português ou publicadas no Brasil. In: Fragmentos, 17, 1999: 95-111. Disponível em: বhttp:// www. periodicos. ufsc. br/ index. php/ fragmentos/article/ view/ 6371/5935>

ENGLEKIRK, John E. Bibliografia de obras norte-americanas em tradução portuguesa (II). In: Revista IberoAmericana, XV, 29, 1949: 149-90. Disponível em: <http:// revistaiberoamericana. pitt. edu/ oj s/index. php/ Iberoamericana/ issue/ view/ 7 $5>$

FIGUEIREDO, Vivina C. Fortuna Literária de Edgar Allan Poe Traduzido em Portugal. In: Cadernos de Tradução, II, 24, 2009: 65-96. Disponível em:

http:// www. periodicos. ufsc. br/ index. php/traducao/ article/ view/ 131 80/ 12218>

MedeIROS, Ruby F. Índice de contos de fiç̧ão científica e fantástico. Porto Alegre: Laboratório-Escola de Ficção Científica Robert A. Heinlein, 1999.

MILTON, John. O Clube do Livro e a tradução. Bauru: EDUSC, 2002. 